\title{
A review on The Common Agricultural Policy in the European Union and the implications for China
}

\author{
Yuhao Qian 1. a and Junshi Chen 2, b \\ ${ }^{1}$ Nanjing University of Finance\&Economics, Institute of Food Economics,Nanjing,China \\ ${ }^{2}$ Massey University, Massey Business School, School of Economics and Finance, New Zealand \\ a qshuaiest@126.com, 'b2805385592@qq.com
}

\begin{abstract}
Keywords: European Union, Common Agricultural Policy, Tariff and Price Support, Chinese Agricultural Policy
\end{abstract}

\begin{abstract}
Many developed countries have built the complete theoretical system for the support and protection of agriculture and formulated agricultural laws. The Common Agricultural Policy is a typical example which ensured food security, improved the effective supply of agricultural products, enhanced the competitiveness of EU member states' agricultural products, stabilized the EU's agricultural product price system, increased farmers' income and increased agricultural production efficiency and production performance after established. Due to the distortion of agricultural production and industrial structure, several important reforms have been introduced and have achieved remarkable results. China's agricultural development has achieved remarkable achievements in the world for decades, but at the same time it has exposed some problems, such as insufficient agricultural investment, backward agricultural science and technology and other issues. The discussion of the Common Agricultural Policy has profound implications for the development of contemporary Chinese agriculture.
\end{abstract}

\section{Introduction}

Agriculture is the fundamental industry of national economy which has significant strategic position. With the rapid development of economic globalization, the food security issue cannot be ignored and the importance of agricultural production is ever pronounced than before. Agriculture has the character of large investment, high risks and long pay-back circle, compared with other economic sectors. Besides of that, the production decisions made by farmers always lag behind due to lack of information about current market demand-and-supply conditions which results in nonsustainable and unhealthy agricultural development. Therefore, agricultural development must rely on the support and protection from the government. This essay mainly summarized the Common Agricultural Policy (“CAP” for short) in European Union (EU) which included three parts. The first part introduced the background of the European Union and Common Agricultural Policy, then analyzed the theoretical basis of CAP, associated with some achievements and problems that the CAP has made. The second part introduced the several reforms of the CAP during the European Economic Community and the European Union established and analyzed the background, the content and the effect of the reform especially from the perspective of price support policy and environmental protection. The last part mainly discussed the role of CAP played in EU development process.

\section{The establishment of the policy}

Before 1957, most western European countries had a serious shortage of meat, fat and other food supplies. At that time, the relatively common in Western Europe was small farms. The organization of agricultural production was incomplete and production efficiency was not high so that farmers had few remaining products to enter the market beyond their basic survival needs. Overall, relative to other social classes, the income of farmers was extremely low. Due to that, many countries' 
governments tried to avoid fluctuations in domestic and foreign demand, stabilize the prices of agricultural products and improve their farmers' incomes in the mid-50s. The establishment of a common agricultural product market and the implementation of a common agricultural policy means that the protection and intervention of agriculture will become the common responsibility for every union members. And any country will not suffer significant losses because of the openness of the agricultural market (Lindberg, 1963). According to the Treaty of Rome signed by the six countries of the Communities in 1957, the objectives of the common agricultural policy included the target of farmers' income, the target of agricultural structure, the target of agricultural products, and the goal of rural development. The specific content is still renewing and developing until now. According to OECD (2013), the CAP is composed of two pillars. Pillar I defines and funds market measures under the Common Market Organization, and includes the Single Payment Scheme (SPS) and the Single Area Payment Scheme (SAPS). Pillar II, or Rural Development Regulation of Agenda 2000, contains various measures co-financed by EU member countries, including agrienvironmental schemes, payments to less favored areas (LFA) and investment assistance. Main approaches like maintaining internal prices above world levels, insulating domestic markets from external competition and intervention buying are commonly used in the policy. After the implementation of the CAP, the agricultural productivity of all member states of the EU has increased rapidly. Between 1961-1969, 1970-1973, 1974-1978 and 1979 -1989, the average annual growth rate of the overall agricultural labor productivity of the European Community was 7.1\%, $6.6 \%, 3.7 \%$ and $4.3 \%$, respectively. The increase in productivity of the overall economy over the same period also exceeded the increase in labor productivity in the industrial sector (Piers, 2005). Secondly, the supply of agricultural products were well guaranteed and market prices were more stable, so that farmers' income increased rapidly.

\section{The reforms of the policy}

Although the CAP has ensured food security and promote the integration of the EU market since the implementation of the efforts, but it still cannot be neglected that the financial pressures, excessive subsidies, distorted resource allocation, and other deficiencies the CAP causes. It is mainly caused by the distortion of agricultural production and industrial structure. According to Demekas (1987), under the stimulation of high financial subsidies, agricultural production has a strong dependence on financial subsidies, which reduces the market sensitivity of agriculture in EU countries. Once the government increases the subsidy for a certain product, the product will flood into the market. When the subsidy for the product is reduced, the industry will be greatly impacted. So it is no longer the price that regulates the market, but the policy that really matters. At the same time, the issues of ecological environmental protection and sustainable development are increasingly prominent. Because of the subsidy method resulted in the scale of production which ensures that a more significant scale of benefits can be obtained. However, the intensive production organization forms caused a serious decline in land quality and overuse of land resources. Therefore, how to incorporate as many environmental-friendly regulations in the CAP as possible so as to ensure the coordination of agricultural development and environmental protection is becoming the serious problem that needs to be solved. Due to some problems that should not be neglected such as market mechanism distortion, the resources inefficient allocation, the heavy fiscal budget burden, during the past fifty years, the European Union Common Agricultural Policy has been reformed on many occasions, including reforms before 1980s, the 1980 reform, the 1992 reform, the Agenda 2000 and the 2003 reform. In general, every reform of agricultural policy dues to its respective and different background, intrinsic driving power as well as external pressure factor. This essay mainly discusses about the Agricultural Support Price policy and Environment-protection policy. The Mansholt Plan before 1980s, Policy of Milk Quota in 1980, and the Stabilizer Policy adopted in 1980s were adjustment to the price support policy which under the Union's internal budget pressure. As shown in graph 1-1: 


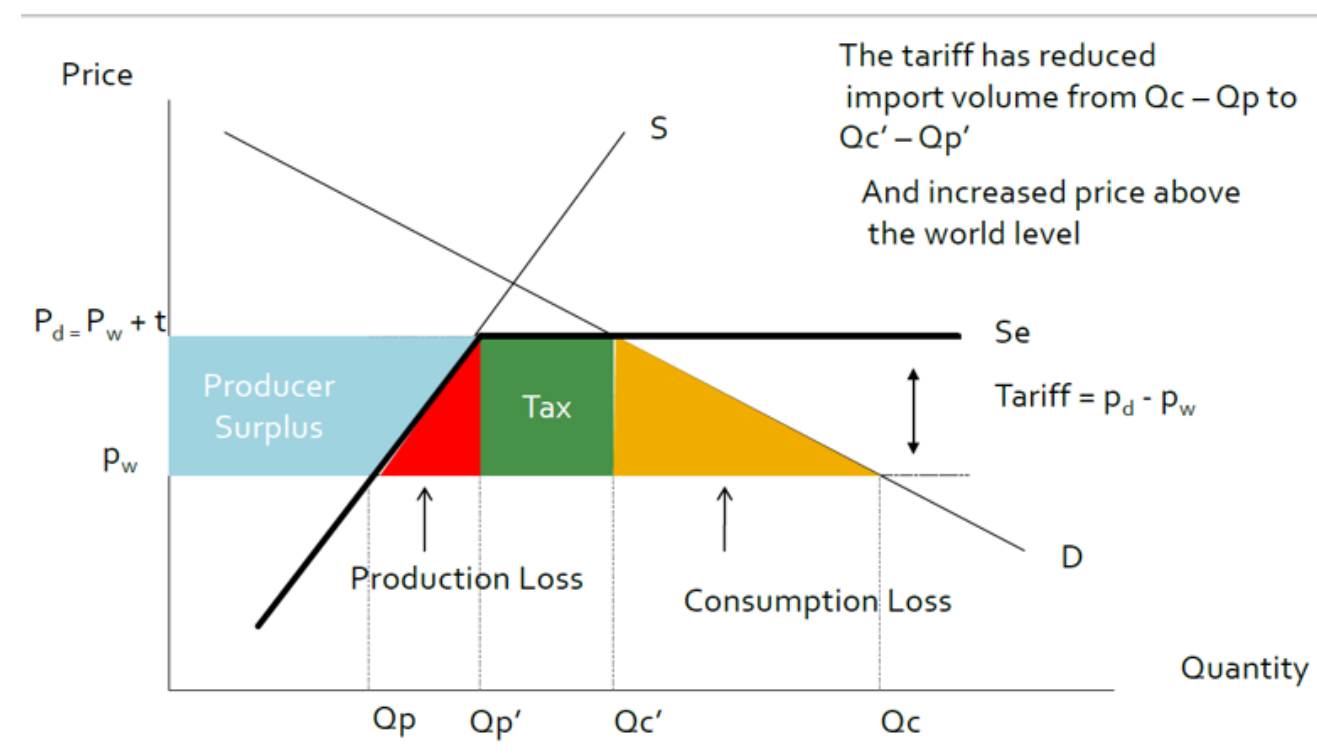

1-1

The domestic demand and domestic supply curve for certain agricultural products in the European Union are D, S respectively, $\mathrm{Pw}$ is the equilibrium world price. In this case, domestic production is Qp, the number of import quantity is Qc-Qp. This is the result of competition in the international market. The EU imposes a tariff on the agricultural products for the protection of internal producers, so new price now is Pd, the import volume is Qc'-Qp'. The tariffs imposed on agricultural products have the following effects: (1) The price paid by the consumer is improved from Pw to Pd. (2) The amount of consumption is reduced to Qc'. (3) Domestic producers face higher market prices and supply conditions have improved. (4) The government can obtain from the tariff collection (The green rectangle area). Overall, the government and domestic producers benefit from tariff policies, while consumer surplus suffers losses. After the tariff is collected, there is a redistribution of income between the consumer and the producer, and the rate of allocation of resources has also been reduced. This is the fact that the gains of the government and domestic producers cannot compensate for the losses suffered by consumers. Therefore, the net loss caused by the tariff policy is Production Loss area and Consumption Loss area. The above analysis shows that the benefits of the tariff protection policy implemented by the EU will be less than the cost, which will result in the failure of the price mechanism and the distortion of the economy. Therefore, the European Union began to drastically reduce price support and replaced it with a direct income subsidy, which has significantly reduced implementation costs and achieved remarkable results since 1992 (Piers, 2005). On the other hand, the agenda 2000 and the reform 2003 focus on several new targets, such as rural development, environmental protection and etc. In the “Agenda 2000", the environmental standards began to be linked to decoupling subsidies in order to achieve the promotion and sustainable development of agriculture. This reflects that environmental issues are causing more and more attention. The main theoretical basis of environment-protection is the theory of the internalization of environmental costs. According to Ferron-Vilchez, De la TorreRuiz \& Ortiz-de Mandojana (2015), the graph 2-1 shows that environmental pollution will destroy the living environment. It has strong externalities. Assume that a factory discharges sewage into a river, which will cause a series of external costs: loss of water quality, fish deaths, etc., leading to social marginal costs of pollution MSB more than the private marginal cost MPB. The manufacturer's production quantity is decided by MPB = MC, Qa; Social optimal yield decided by MSB=MC, Q1 which is less than Qa. Therefore, when external costs fail to achieve internalization, the output will exceed the optimal social output, which will result in inefficient resource allocation. 


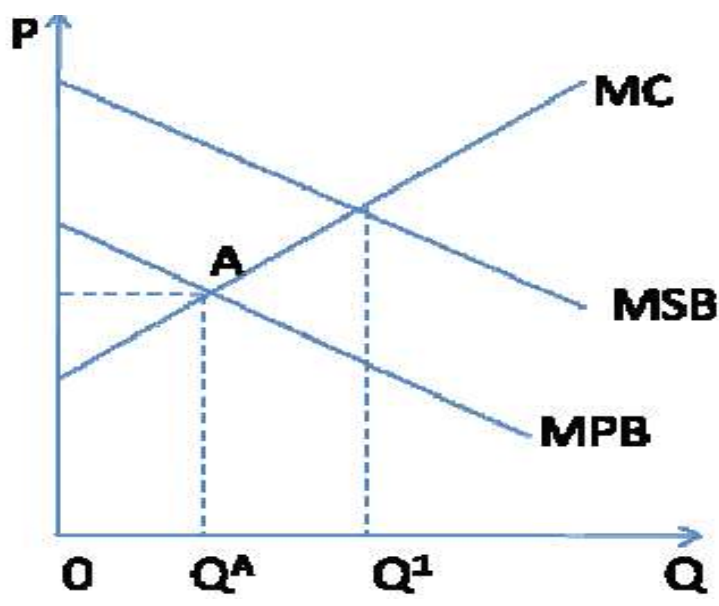

$2-1$

The measure of the internalization of environmental costs refers to make additional costs imposed on the manufacturers of emissions. The implementation of this method will reduce the amount of pollutants emitted by producers and make the pollution above the social optimal level.The following analysis is based on the graph 2-2.

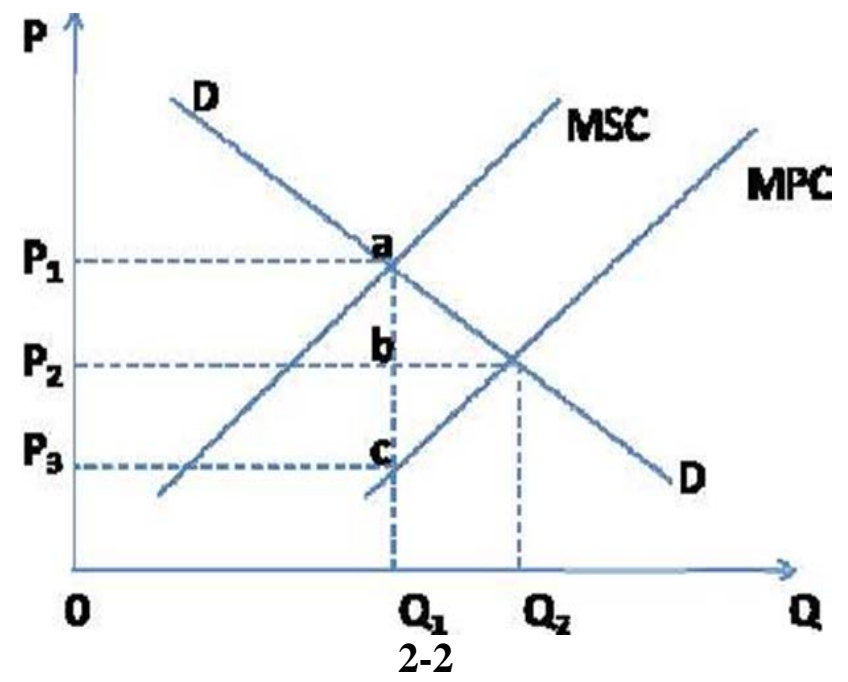

The horizontal axis and the vertical axis represent the amount of pollution caused by the production and the price of the product, respectively. Manufacturers' marginal cost curve is MPC. When the environmental cost internalization measures are not implemented, the market equilibrium output is Q2 and the equilibrium product price is $\mathrm{P} 2$. As the pollution emitted by the manufacturers has extra negative impact for other social groups, so MPC curve does not reflect the cost loss caused by the manufacturer's actions to the entire society. If a policy is designed to internalize the external costs caused by pollution to the manufacturer, for example, each unit of a manufacturer's product may cause 100 Dollar damage to other social groups due to increased pollution emissions, then, the government impose 100 Dollar additional taxes on each unit of the manufacturer's product, so it is equivalent to shifting the marginal cost curve upwards to MSC. Therefore, the manufacturer's pollution emissions will be fall to Q1 which is consistent with the social optimal pollution standards. At the same time, the price faced by consumers rise to $\mathrm{P} 1$, and the price accepted by the manufacturer is lower to P3. In the graph, the total pollution tax is ac, the producer bears bc while the consumer assumes the rest ab. In fact, during several reforms, UN has considered the agricultural and economic development condition of the all UN members and adjusted the policies, thus the budget pressure has been alleviated and environment has been changed gradually. All these changes has made the function of CAP strengthened. 


\section{The implications of CAP for the Chinese agriculture policy}

The current problems in the development of agriculture in China with weak infrastructure and low levels of agricultural science and technology are closely related to insufficient agricultural financial support. From the point of view of CAP, one of the important factors that the EU member states have been able to make great achievements is the abundant financial support. Two-thirds of the EU's total budget has been used for agricultural funding. Based on the process of reform and implementation of the CAP, the European Union is subsidizing farmers through various ways, and the agricultural income gap among the members has been substantially eliminated. Strictly implementing the direct subsidy policy, establishing a sound agricultural product market system, and improving the market circulation mechanism of agricultural products are the key to ensure China's agricultural production stable and farmers' income increasing continuously. In addition, the CAP's approaches that combines agriculture and the environment is well worth learning by China, which is increasingly facing environmental pollution problems. In rural Europe, it is hardly to see drastic constructions, only the original features of tradition and nature. It can be said that CAP has a clear ecological direction.

\section{Conclusion}

As an important agricultural policy in the world, the EU's common agricultural policy was established to ensure food security, increase productivity, stabilize the EU's agricultural product price system, increase farmers' income and increase agricultural production efficiency. It should not be overlooked that while the CAP has achieved tremendous achievements, it has also brought about problems such as the distortion of the market mechanism, the misallocation of resource allocation, and the heavy budget burden. Making every effort to reverse policy mistakes and realize the optimization and maximization of CAP performance is always the subject of current and future CAP adjustments and reforms. After 60 years of development, several important reforms have made significantly achievements, which have profound implications for the development of contemporary Chinese agriculture.

\section{References}

[1] Demekas, D. G. (1987). The Effects of the Common Agricultural Policy of European Communities. International Monetary Fund, 7(2), 181-187.

[2] Ferron-Vilchez, V., de la Torre-Ruiz, J. M., \& Ortiz-de Mandojana, N. (n.d). (2015). How much would environmental issues cost? The internalization of environmental costs in the european transport industry. Environmental Engineering and Management Journal, 14(9), 2149-2162.

[3] Gorter, H. D., Meilke, K.D. (1991). American Agricultural Economics Association, American Journal of Agricultural Economics, 73(2), 535-537.

[4] Lindberg, L. N. (1963). The Political Dynamics of European Integration, London, 221-222.

[5] OECD. (2013). “European Union”, in Agricultural Policy Monitoring and

[6] Evaluation. OECD Countries and Emerging Economies, OECD Publishing.

[7] Piers, L. N. (2005). "The Making of the CAP: Towards a Historical Analysis of the EU's First Major Policy." Contemporary European History, 14(3), 349-350. 